Journal of Clinical Investigation

Vol. 42, No. 9, 1963

\title{
DISSOCIATION BETWEEN FILTERED LOAD OF SODIUM AND ITS RATE OF EXCRETION IN THE URINE *
}

\author{
By WILLIAM B. BLYTHE † AND LOUIS G. WELT
}

(From the Department of Medicine, University of North Carolina School of Medicine, Chapel Hill, N. C.)

(Submitted for publication July 5, 1962; accepted May 31, 1963)

Sodium appearing in the urine presumably represents the difference between the amount filtered at the glomerulus and that which leaves the tubular lumen as the filtrate courses through the nephron. The rate of urinary sodium excretion $\left(\mathrm{U}_{\mathrm{Na}} \mathrm{V}\right)$ can be modified, therefore, by changes in the filtered load [glomerular filtration rate $(G F R) \times$ plasma sodium concentration $\left.\left(\mathrm{P}_{\mathrm{Na}}\right)\right]$, or the degree of tubular reabsorption, or both.

Since $\mathrm{U}_{\mathrm{Na}} \mathrm{V}$ under most circumstances represents only about $1 \%$ of the filtered load, it is evident that minor changes in filtered load might result in major changes in $\mathrm{U}_{\mathbf{N a}} \mathrm{V}$. It is not possible at present to assess small changes in filtered load of sodium because of the magnitude of error involved in measuring GFR. Thus, it is not reasonable to ascribe a change in $\mathrm{U}_{\mathrm{Na}} \mathrm{V}$ to a variation in tubular reabsorption simply because there is no apparent change in the filtered load. Furthermore, the uncertainty involved in measuring small changes in filtered load of sodium has afforded difficulty in delineating the role of each of its components, $\mathrm{P}_{\mathrm{Na}}$ and $\mathrm{GFR}$, in regulating sodium excretion, largely because maneuvers designed to alter these components also tend to alter the filtered load in the same direction.

The bulk of evidence, when subjected to critical review $(2,3)$, supports the view that acute changes in $\mathrm{U}_{\mathrm{Na}} \mathrm{V}$ can be accounted for by fluctuations in filtered load.

The present study examines the relationship between filtered load of sodium and $\mathrm{U}_{\mathrm{Na}} \mathrm{V}$ when $\mathrm{P}_{\mathrm{Na}}$ is increasing and filtered load is decreasing as a consequence of the infusion of a solution of

* This investigation was supported by grant H-1301 from the U. S. Public Health Service. A preliminary report was published in abstract form (1).

$\dagger$ Part of this work was done during the tenure of a Life Insurance Medical Research Fund Fellowship. hypertonic saline and the simultaneous disproportionate depression of GFR.

The results suggest that under these circumstances there is not a direct relationship between filtered load and $\mathrm{U}_{\mathrm{Na}} \mathrm{V}$, and that $\mathrm{U}_{\mathrm{Na}} \mathrm{V}$ is in some manner related to $\mathrm{P}_{\mathrm{Na}}$.

\section{METHODS}

The experimental animals were anesthetized female mongrel dogs weighing 10 to $15 \mathrm{~kg}$. The experiments were performed in the morning, and neither food nor water was restricted before the experiments. The animals were fed regular commercial kennel rations and were not sodium depleted. Anesthesia was produced with iv sodium pentobarbital $(25 \mathrm{mg}$ per $\mathrm{kg}$ body weight).

Exogenous creatinine clearance was taken as a measure of GFR except in experiment 1, in which inulin clearance was used. Sustaining infusions of creatinine or inulin consisted of appropriate amounts of these substances in $0.9 \%$ saline infused in a foreleg vein at $1.0 \mathrm{ml}$ per minute. At least $\mathbf{4 0}$ minutes was allowed for equilibration of the creatinine or inulin priming solutions.

Urine was collected via an indwelling catheter. Completeness of collections was assured by rinsing the bladder with distilled water followed by rinsing with $100 \mathrm{ml}$ of air at the end of each collection period. (Only air rinses were used in experiment 1.) The collection periods were 30 to 40 minutes long in most instances.

Blood was taken at the mid-point of the urine collections from an inlying needle in a femoral artery.

Creatinine was determined by the method of Knowlton (4) and inulin by the method of Walser, Davidson, and Orloff (5). Sodium determinations were made with a Baird internal-standard flame photometer.

Experimental design. $\mathrm{P}_{\mathrm{Na}}$ was increased by infusing a $5 \%$ sodium chloride solution, and GFR was decreased by inflation of a balloon in the inferior vena cava. The following experimental procedure was followed. After anesthetization, a sterile catheter with a $10-\mathrm{ml}$ inflatable balloon was inserted via the femoral vein into the inferior vena cava distal to the renal veins. A Cournand needle was inserted into a femoral artery. In some of the experiments, an infusion of $2 \frac{1}{2} \%$ glucose solution was employed to assure adequate urine flow. After allowing time for equilibration of the creatinine infusion, two 
or three control periods were obtained. After the control periods, an infusion of $5 \%$ sodium chloride solution was begun, the balloon in the inferior vena cava was inflated, and the experiment was continued for 3 to 7 more periods. To assure marked diminution in GFR in some of the experiments, blood volume was reduced in amounts equivalent to $5 \%$ of body weight by bleeding from the femoral artery.

\section{RESULTS}

Nine experiments in nine dogs were performed. In four experiments, the filtered load of sodium during every one of the experimental periods was clearly less than the control values, yet $\mathrm{U}_{\mathrm{Na}} \mathrm{V}$ was unequivocally increased in all but three periods. A summary of the data from these four experiments is shown in Table $\mathrm{I}$. The mean filtered load of sodium of all the experimental periods was $65 \%$ of the control val- ues, and the range was from $7 \%$ to $91 \%$ of the control values.

In five other experiments, $\mathrm{U}_{\mathrm{Na}} \mathrm{V}$ invariably increased and filtered load was generally depressed during the experimental periods; however, GFR was not always low enough to offset the effect of increasing $\mathrm{P}_{\mathrm{Na}}$ on filtered load, so that the filtered load was not unequivocally diminished in every experimental period. The values for filtered load and $\mathrm{U}_{\mathrm{Na}} \mathrm{V}$ from these experiments, along with comparable data from experiments 1 to 4 , were plotted on fourfold graphs and are shown in Figure 1. The points on the graph represent the actual deviations from mean control values. In only one period was the filtered load increased over the mean control value by more than $2 \mathrm{SD}$, and in five other periods the filtered load was increased over control val-

TABLE I

Summary of data from experiments 1 to $4^{*}$

\begin{tabular}{|c|c|c|c|c|c|c|c|}
\hline \multirow[t]{2}{*}{ Exp't. } & Period $\dagger$ & V & GFR & $\mathrm{P}_{\mathrm{Na}}$ & Filtered & 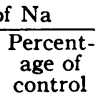 & $\mathrm{U}_{\mathrm{Na}} \mathrm{V}$ \\
\hline & & $m l / m i n$ & $m l / \min$ & $m E q / L$ & $\mu E q / \min$ & $\%$ & $\mu E q / \min$ \\
\hline 1 & $\begin{array}{l}\text { Con. } \\
\text { Con. } \\
\text { Exp. } \\
\text { Exp. } \\
\text { Exp. } \\
\text { Exp. }\end{array}$ & $\begin{array}{r}.23 \\
.18 \\
1.90 \\
2.02 \\
3.40 \\
3.10\end{array}$ & $\begin{array}{l}51.9 \\
59.9 \\
37.6 \\
28.1 \\
39.7 \\
36.7\end{array}$ & $\begin{array}{l}150.1 \\
148.3 \\
167.0 \\
174.0 \\
174.0 \\
179.0\end{array}$ & $\begin{array}{l}7,790 \\
8,883 \\
6,279 \\
4,889 \\
6,908 \\
6,587\end{array}$ & $\begin{array}{l}75 \\
59 \\
83 \\
79\end{array}$ & $\begin{array}{r}14 \\
16 \\
479 \\
515 \\
877 \\
793\end{array}$ \\
\hline 2 & $\begin{array}{l}\text { Con. } \\
\text { Con. } \\
\text { Exp. } \\
\text { Exp. } \\
\text { Exp. } \\
\text { Exp. } \\
\text { Exp. }\end{array}$ & $\begin{array}{r}.27 \\
.20 \\
.17 \\
.15 \\
1.40 \\
1.40 \\
2.00\end{array}$ & $\begin{array}{r}46.4 \\
40.0 \\
5.6 \\
2.8 \\
16.3 \\
14.6 \\
20.3\end{array}$ & $\begin{array}{l}150.5 \\
149.7 \\
159.0 \\
162.1 \\
167.0 \\
172.8 \\
173.5\end{array}$ & $\begin{array}{r}6.983 \\
5,988 \\
890 \\
454 \\
2,714 \\
2,523 \\
3,522\end{array}$ & $\begin{array}{r}14 \\
7 \\
42 \\
39 \\
54\end{array}$ & $\begin{array}{r}51 \\
29 \\
43 \\
28 \\
265 \\
281 \\
392\end{array}$ \\
\hline 3 & $\begin{array}{l}\text { Con. } \\
\text { Con. } \\
\text { Exp. } \\
\text { Exp. } \\
\text { Exp. } \\
\text { Exp. } \\
\text { Exp. } \\
\text { Exp. } \\
\text { Exp. }\end{array}$ & $\begin{array}{l}.33 \\
.29 \\
.36 \\
1.31 \\
3.45 \\
2.98 \\
3.14 \\
2.00 \\
2.54\end{array}$ & $\begin{array}{l}80.9 \\
87.8 \\
74.6 \\
56.2 \\
57.3 \\
59.9 \\
62.0 \\
62.0 \\
60.5\end{array}$ & $\begin{array}{l}147.0 \\
142.8 \\
150.0 \\
154.5 \\
159.5 \\
162.7 \\
163.2 \\
165.5 \\
167.0\end{array}$ & $\begin{array}{r}11,892 \\
12,538 \\
11,190 \\
8,623 \\
9,139 \\
9,746 \\
10,118 \\
10,261 \\
10,104\end{array}$ & $\begin{array}{l}91 \\
71 \\
75 \\
79 \\
83 \\
84 \\
83\end{array}$ & $\begin{array}{r}5 \\
3 \\
5 \\
339 \\
847 \\
844 \\
872 \\
612 \\
776\end{array}$ \\
\hline 4 & $\begin{array}{l}\text { Con. } \\
\text { Con. } \\
\text { Exp. } \\
\text { Exp. } \\
\text { Exp. } \\
\text { Exp. }\end{array}$ & $\begin{array}{r}.27 \\
.21 \\
.35 \\
.97 \\
1.03 \\
.56\end{array}$ & $\begin{array}{l}56.8 \\
56.4 \\
44.0 \\
37.3 \\
39.5 \\
26.6\end{array}$ & $\begin{array}{l}135.0 \\
134.3 \\
144.3 \\
155.0 \\
151.5 \\
173.7\end{array}$ & $\begin{array}{l}7,668 \\
7,575 \\
6,349 \\
5,782 \\
5,984 \\
4,620\end{array}$ & $\begin{array}{l}83 \\
76 \\
79 \\
61\end{array}$ & $\begin{array}{r}4 \\
5 \\
53 \\
239 \\
256 \\
105\end{array}$ \\
\hline
\end{tabular}

$* \mathrm{~V}=$ urine flow $; \mathrm{GFR}=$ glomerular filtration rate; $\mathrm{P}_{\mathrm{Na}}=$ plasma sodium concentration; $\mathrm{U}_{\mathrm{Na}} \mathrm{V}=$ rate of urinary sodium excretion.

† Con. = control; exp. = experimental. 


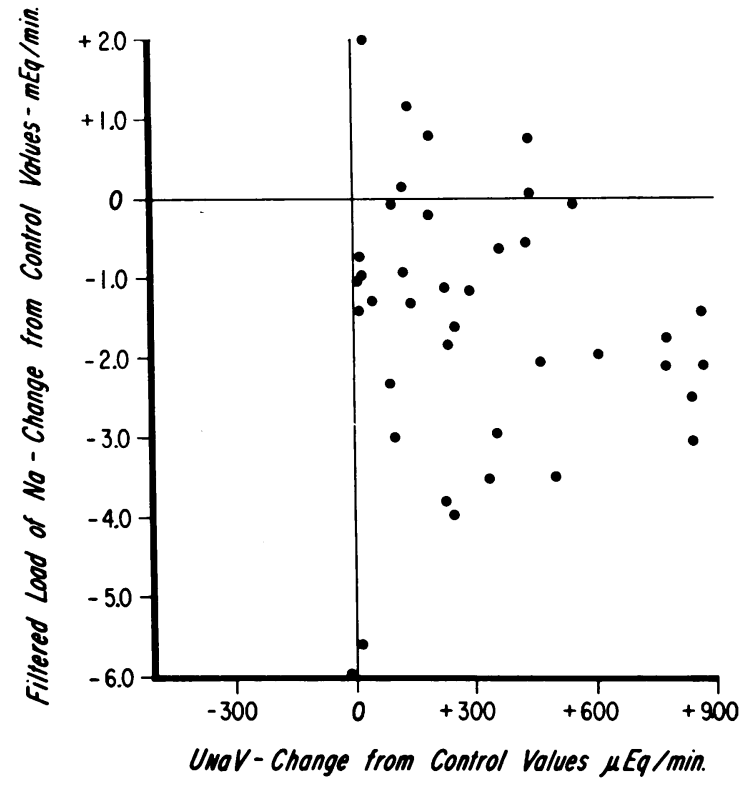

Fig. 1. Fourfold Graph illustrating the Changes FROM CONTROL VALUES OF RATE OF URINARY SODIUM EXCRETION $\left(\mathrm{U}_{\mathrm{Na}} \mathrm{V}\right)$ AND THE FILTERED LOAD OF SODIUM.

ues by less than $2 \mathrm{SD}$. The remainder of the values for filtered load during the experimental periods was less than the control values, and the difference in most instances was greater than $2 \mathrm{SD}$ of the mean control values.

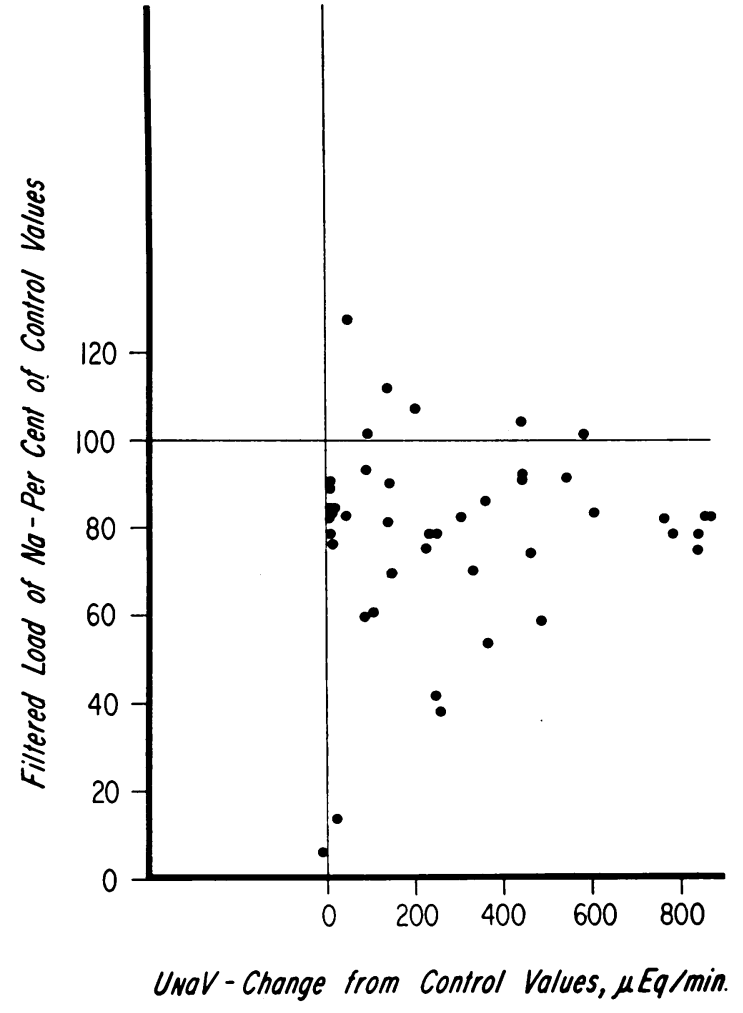

Fig. 2. Fourfold Graph illustrating the RelationSHIP BETWEEN $\mathrm{U}_{\mathrm{xa}} \mathrm{V}$ AND THE FILTERED LOAD OF SODIUM. Filtered load is plotted as percentage of control value.

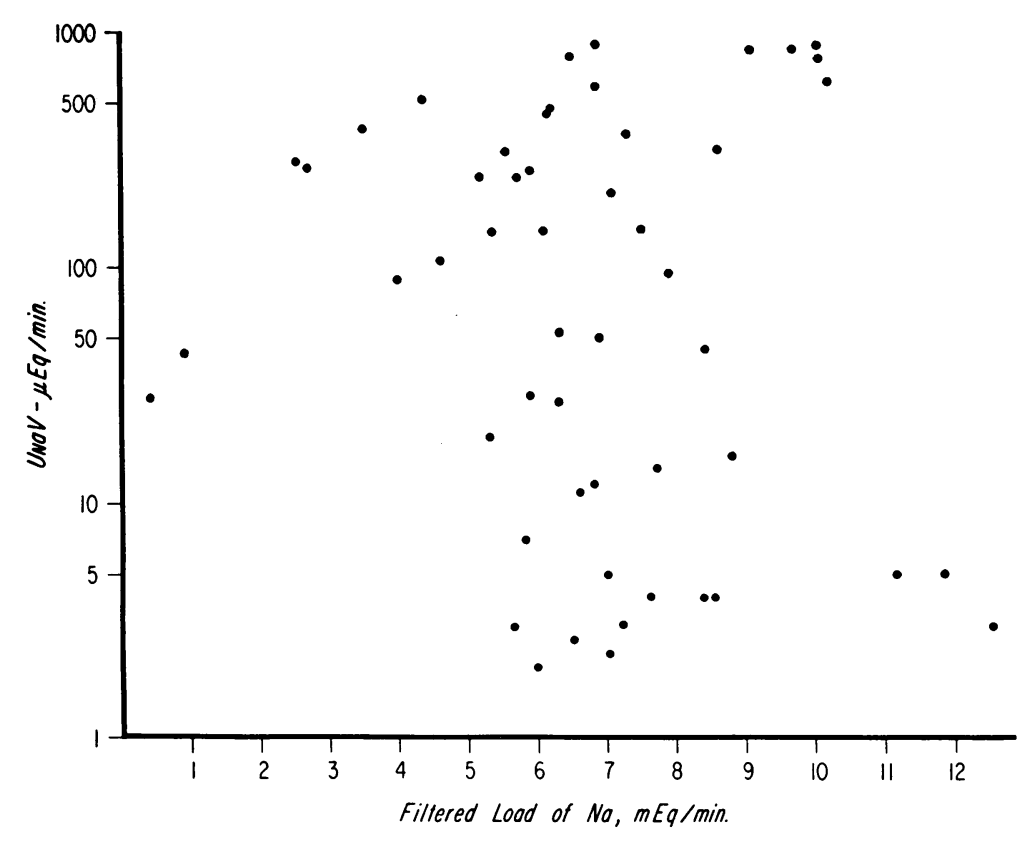

Fig. 3. Relationship between $\mathrm{U}_{\mathrm{Na}} \mathrm{V}$ and the filtered load of Sodicm. 


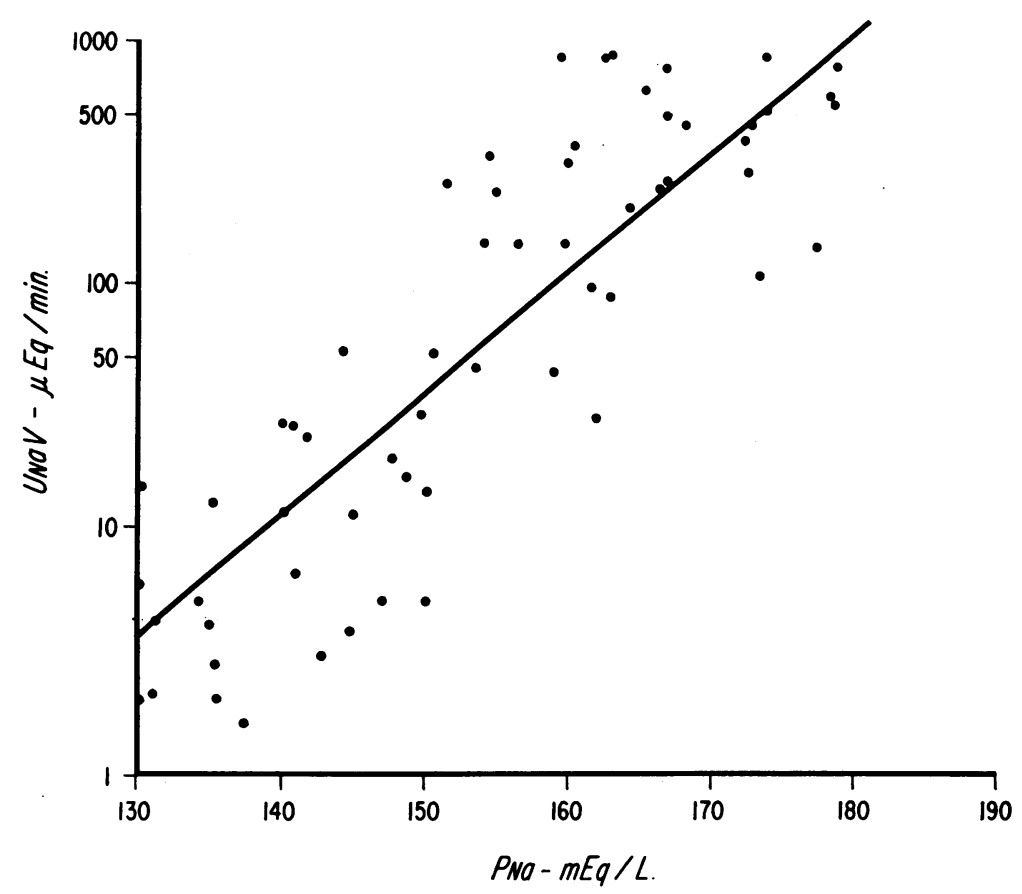

Fig. 4. Relationship between $U_{\mathrm{Na}} \mathrm{V}$ and plasma sodium Concentration.

To illustrate the magnitude of the depression of the filtered load, the change in filtered load expressed as percentage of the mean control value was plotted and is shown in Figure 2.

There was no linear correlation observed between $\mathrm{U}_{\mathrm{Na}} \mathrm{V}$ and filtered load of sodium. There was also lack of correlation between the logarithm of $\mathrm{U}_{\mathrm{Na}} \mathrm{V}$ and the filtered load as seen in Figure 3.

When the relationship between $\mathrm{U}_{\mathrm{Na}} \mathrm{V}$ and $\mathrm{P}_{\mathrm{Na}}$ was examined, however, linear correlation between the logarithm of $\mathrm{U}_{\mathrm{Na}} \mathrm{V}$ and $\mathrm{P}_{\mathrm{Na}}$ was found as shown in Figure 4 . The equation logarithm $\mathrm{U}_{\mathrm{Na}} \mathrm{V}=\alpha+\beta \mathrm{P}_{\mathrm{Na}}$ was fitted to the data by the method of least squares, and the regression equation was found to be: logarithm $\mathrm{U}_{\mathrm{Na}} \mathrm{V}=-5.83$ $+0.0492 \mathrm{P}_{\mathrm{Na}}$. Testing the hypothesis that $\beta$ is significantly different from zero by the " $F$ " test results in $p<.01$ ("F" with 1 and 59 degrees of freedom $=166.26$ ), signifying a statistically significant relationship between logarithm $\mathrm{U}_{\mathrm{Na}} \mathrm{V}$ and $\mathrm{P}_{\mathrm{Na}}$. Whether the relationship defined by the regression equation was consistent among the experimental animals was also examined, and it was found that the slopes varied significantly. However, the relationship defined by the average regression line remains highly significant even when the variation among slopes is taken into account. ("F" with 1 and 8 degrees of freedom $=58.22$ ).

\section{DISCUSSION}

The study indicates that under the circumstances of the experiments there need not be a direct relationship between the filtered load of sodium and $\mathrm{U}_{\mathrm{Na}} \mathrm{V}$; however, the mechanisms whereby $\mathrm{U}_{\mathrm{Na}} \mathrm{V}$ is increased despite a lowered filtered load of sodium cannot be established with certainty. It is possible that as GFR is diminished, blood flow is completely diverted from some glomeruli so that filtration in these glomeruli ceases, and as $\mathrm{P}_{\mathrm{Na}}$ is elevated, the load of sodium presented to the functioning glomeruli is increased. There is, therefore, this possibility that the heightened $\mathrm{U}_{\mathrm{Na}} \mathrm{V}$ is secondary to an increased filtered load of sodium.

Conversely, if it is assumed that filtration is decreased uniformly in all glomeruli, it follows that the increase in $\mathrm{U}_{\mathrm{Na}} \mathrm{V}$ is a consequence of diminished net sodium reabsorption somewhere along the course of the tubule. Further, the implication is that there is either an actual decrease in 
sodium reabsorption in some sites in the tubule, or that there is an increase in the movement of sodium from the renal interstitium into the tubular lumen. Decrease in sodium reabsorption might have been effected by a diminution in aldosterone secretion which, in turn, was promoted by the infusion of hypertonic sodium chloride solution. Although this mechanism cannot be excluded, it seems unlikely because of the short interval between the start of the infusion and the increase in $\mathrm{U}_{\mathrm{Na}} \mathrm{V}$.

It is also unlikely that movement of sodium from the medullary interstitium into the collecting tubule could account for the findings, since it has been shown in both the rabbit (6) and the dog (7) that when $\mathrm{Na}^{22}$ is injected into the renal artery during a period of stopped flow, there is little or no movement of sodium from plasma into the tubular lumen distal to the site of the production of the sodium trough.

If there is neither an actual decrease in sodium reabsorption in the distal portions of the nephron nor movement of sodium from the interstitium into the collecting tubule during the time that $\mathrm{U}_{\mathrm{Na}} \mathrm{V}$ is increasing, it follows that the sodium reabsorptive capacity of the distal and collecting tubules has been exceeded, despite a smaller filtered load of sodium.

It is possible that, for some unknown reason, the amount of sodium reabsorbed proximally was lessened when the filtered load was decreased, thereby allowing a larger load of sodium to be presented to the ascending limb of Henle's loop and the distal and collecting tubules, so that the sodium reabsorptive capacity in these segments was exceeded. Although this hypothesis cannot be excluded, the available evidence $(8,9)$ makes it unlikely. In contrast, it would be anticipated that the absolute quantity of sodium that escapes reabsorption in the proximal convolution would be diminished.

There is a possibility that the increase in the concentration of sodium in the interstitial fluid of the cortico-medullary and cortical areas of the kidney, effected by the infusion of hypertonic saline solution, provided a steeper concentration gradient for passive diffusion of sodium from the interstitium into the tubular fluid of these areas where luminal sodium concentration is diminished. The resulting increase in passive diffusion of sodium into the tubular lumen might be large enough to exceed the amount of sodium transported out of the lumen so that the net effect would lead to a heightened $\mathrm{U}_{\mathrm{Na}} \mathrm{V}$.

Another explanation for the findings is one suggested by a model proposed by Morel (10). It is conceivable that the experimental conditions were such as to increase the sodium concentration of the medullary interstitium, which in turn would afford a steeper gradient from the medullary interstitium into the lumen of the descending limb of Henle's loop. The diffusion of sodium from the medullary interstitium would be increased, and hence, the load delivered to the ascending limb of Henle's loop would likewise increase. This might, initially, result in sufficient extrusion of sodium from the limb so as to compensate for the augmented quantity delivered to this site. Ultimately, however, this effect might be self-defeating and the load of sodium presented to the ascending limb could be so great as to exceed the reabsorptive capacity of these segments, and $\mathrm{U}_{\mathrm{Na}} \mathrm{V}$ would therefore increase. The data do not allow discrimination among these various possibilities and do not preclude other possibilities.

The clear relationship between $\mathrm{U}_{\mathrm{Na}} \mathrm{V}$ and $\mathrm{P}_{\mathrm{Na}}$ is perhaps surprising in that variables that might influence $\mathrm{U}_{\mathrm{Na}} \mathrm{V}$ in opposing directions are presumably in operation, and it might be expected that these would tend to obscure any such relationship. Nevertheless, the data show that $\mathrm{U}_{\mathrm{Na}} \mathrm{V}$ is being influenced by $\mathrm{P}_{\mathrm{Na}}$ or a function thereof. Although this relationship is consistent with the idea that the increased $\mathrm{U}_{\mathrm{Na}} \mathrm{V}$ results from passive diffusion of sodium from some portions of the renal interstitium into the tubular lumen, it does not preclude other possibilities. Further, it is possible that the relationship is fortuitous, since it has been shown in the dog by deWardener, Mills, Clapham, and Hayter (11) and Levinsky and Lalone (12) that increased sodium excretion can be achieved despite a decreased filtered load of sodium when isotonic saline solution is employed as a sodium loading solution.

Goldsmith, Rector, and Seldin (13) have recently produced evidence for a direct effect of $P_{N: 1}$ on sodium excretion. They found that $U_{N: i} V$ was much less during mannitol diuresis in dogs that were made chronically hyponatremic than in those with normal $\mathrm{P}_{\mathrm{Na}}$ and suggested that chronic 
hyponatremia might in some manner enhance the ability of the proximal tubule to reabsorb sodium against concentration gradients. It is also possible that their findings can be explained by the converse of the explanations presented in the present discussion.

\section{SUMMARY}

The relationship between filtered load of sodium and the rate of urinary sodium excretion $\left(\mathrm{U}_{\mathrm{Na}} \mathrm{V}\right)$ when plasma sodium concentration was increasing and filtered load decreasing was examined in anesthetized dogs.

No direct relationship between filtered load of sodium and $\mathrm{U}_{\mathrm{Na}} \mathrm{V}$ was found. $\mathrm{U}_{\mathrm{Na}} \mathrm{V}$ was markedly elevated over control values despite a depressed filtered load. Several explanations for the findings are presented.

We concluded that factors other than filtered load influence $\mathrm{U}_{\mathrm{Na}} \mathrm{V}$, and the data imply that plasma sodium concentration may be one of the regulating influences.

\section{ACKNOWLEDGMENT}

Dr. James Grizzle and Dr. Carl-Erik Sarndal performed the statistical analyses.

\section{REFERENCES}

1. Blythe, W. B., and L. G. Welt. Dissociation between filtered load of sodium and its rate of excretion in the urine. Clin. Res. 1959, 7, 274.

2. Selkurt, E. E., Sodium excretion by the mammalian kidney. Physiol. Rev. 1954, 34, 287.
3. Wesson, L. G., Jr. Glomerular and tubular factors in the renal excretion of sodium chloride. Medicine (Baltimore) 1957, 36, 281.

4. Analytical procedures, M. Knowlton, Ed. Washington, D. C., Army Medical Service Graduate School, Walter Reed Army Medical Center, 1955, pp. iv-6.

5. Walser, M., D. G. Davidson, and J. Orloff. The renal clearance of alkali-stable inulin. J. clin. Invest. 1955, 34, 1520.

6. Morel, F., and A. Falbriard. Etude de la permeabilité des diverses parties du nephron pour les ions sodium et potassium. Rev. franç. Etud. clin. biol. 1959, 4, 471.

7. White, H. L., D. Rolf, and D. C. Tosteson. Water and sodium exchange in renal tubule fluid. Amer. J. Physiol. 1961, 200, 591.

8. Giebisch, G., R. M. Klose, and E. E. Windhager. Micropuncture study of renal tubular transfer of sodium and water in the rat during sodium chloride loading. Fed. Proc. 1962, 21, 432.

9. Lassiter, W. E., C. W. Gottschalk, and M. Mylle. Micropuncture study of net transtubular movement of water and urea in rat kidney during saline diuresis. Fed. Proc. 1963, 22, 277.

10. Morel, F. Role de la permeabilité des diverses cellules tubulaires dans la fonction d'excretion de l'eau et des electrolytes. Proc. int. Union physiol. Sci. 1962, 1 (part I), 372.

11. DeWardener, H. E., I. H. Mills, W. F. Clapham, and C. J. Hayter. Studies on the efferent mechanism of the sodium diuresis which follows the administration of intravenous saline in the dog. Clin. Sci. 1961, 21, 249.

12. Levinsky, N. G., and R. C. Lalone. The mechanism of sodium diuresis after saline loading: evidence for a factor other than increased filtered sodium and decreased aldosterone (abstract). J. clin. Invest. 1963, 42, 951.

13. Goldsmith, C., F. C. Rector, Jr., and D. W. Seldin. Evidence for a direct effect of serum sodium concentration on sodium reabsorption. J. clin. Invest. $1962,41,850$. 